\title{
Nerve growth factor improves functional recovery by inhibiting endoplasmic reticulum stress-induced neuronal apoptosis in rats with spinal cord injury
}

Hongyu Zhang ${ }^{1 \dagger}$, Fenzan Wu ${ }^{1,2+}$, Xiaoxia Kong ${ }^{3}$, Jie Yang ${ }^{1}$, Huijun Chen ${ }^{1}$, Liancheng Deng ${ }^{1}$, Yi Cheng ${ }^{1}$, Libing Ye ${ }^{1}$, Sipin Zhu ${ }^{4}$, Xie Zhang ${ }^{5}$, Zhouguang Wang ${ }^{1}$, Hongxue Shi ${ }^{1}$, Xiaobing Fu' ${ }^{6}$, Xiaokun Li ${ }^{1}$, Huazi Xu ${ }^{4}$, Li Lin ${ }^{1 *}$ and Jian Xiao ${ }^{1 *}$

\begin{abstract}
Background: Endoplasmic reticulum (ER) stress-induced apoptosis plays a major role in various diseases, including spinal cord injury (SCI). Nerve growth factor (NGF) show neuroprotective effect and improve the recovery of SCl, but the relations of ER stress-induced apoptosis and the NGF therapeutic effect in SCl still unclear.

Methods: Young adult female Sprague-Dawley rats's vertebral column was exposed and a laminectomy was done at T9 vertebrae and moderate contusion injuries were performed using a vascular clip. NGF stock solution was diluted with $0.9 \% \mathrm{NaCl}$ and administered intravenously at a dose of $20 \mu \mathrm{g} / \mathrm{kg} /$ day after SCl and then once per day until they were executed. Subsequently, the rats were executed at $1 d, 3 d, 7 d$ and $14 d$. The locomotor activities of $\mathrm{SCl}$ model rats were tested by the 21-point Basso-Beattie-Bresnahan (BBB) locomotion scale, inclined plane test and footprint analysis. In addition, Western blot analysis was performed to identify the expression of ER-stress related proteins including CHOP, GRP78 and caspase-12 both in vivo and in vitro. The level of cell apoptosis was determined by TUNEL in vivo and Flow cytometry in vitro. Relative downstream signals Akt/GSK-3 $\beta$ and ERK1/2were also analyzed with or without inhibitors in vitro.

Results: Our results demonstrated that ER stress-induced apoptosis was involved in the injury of SCI model rats. NGF administration improved the motor function recovery and increased the neurons survival in the spinal cord lesions of the model rats. NGF decreases neuron apoptosis which measured by TUNEL and inhibits the activation of caspase-3 cascade. The ER stress-induced apoptosis response proteins CHOP, GRP78 and caspase-12 are inhibited by NGF treatment. Meanwhile, NGF administration also increased expression of growth-associated protein 43 (GAP43). The administration of NGF activated downstream signals Akt/GSK-3 $\beta$ and ERK1/2 in ER stress cell model in vitro.
\end{abstract}

Conclusion: The neuroprotective role of NGF in the recovery of $\mathrm{SCl}$ is related to the inhibition of ER stress-induced cell death via the activation of downstream signals, also suggested a new trend of NGF translational drug development in the central neural system injuries which involved in the regulation of chronic ER stress.

Keywords: Nerve growth factor, Endoplasmic reticulum stress, Spinal cord injury, Apoptosis, Akt/GSK-3ß, ERK1/2

\footnotetext{
*Correspondence: linliwzmc@163.com; xfxj2000@126.com

${ }^{\dagger}$ Equal contributors

'Key Laboratory of Biotechnology and Pharmaceutical Engineering,

Molecular Pharmacology Research Center, School of Pharmacy, Wenzhou

Medical University, Wenzhou, Zhejiang 325035, China

Full list of author information is available at the end of the article
} 


\section{Introduction}

Spinal cord injury (SCI) represents a severe health problem worldwide usually associated with life-long disabilities. SCI often affects individuals in their productive age, having an enormous social and economic impact. Traumatic SCI evolves through two phases: normally, the primary injury and the secondary injury which includes disturbances in ionic homeostasis, local edema, ischemia, focal hemorrhage, free radicals stress and inflammatory response [1]. Substantial research efforts are being devoted to limit the evolution of secondary damage through the development of neuroprotective measures [2]. Several reports have suggested that apoptosis plays a pivotal role in this secondary damage in animal models and in human tissue by causing progressive degeneration of the spinal cord [3]. However, the exact mechanism of cell death has not been fully clarified.

Endoplasmic reticulum is the important intracellular organelle for the synthesis and folding of secreted and membrane-bound proteins and the first site of the secretory pathway [4]. Some of the events triggered by the secondary injury, such as disturbance of calcium homeostasis, accumulation of unfolded or misfolded proteins and hypoglycemia, can trigger ER stress [5,6]. Consequently, to restore the proper function of ER and trigger the unfolded protein response (UPR), contribute to this adverse situation [7]. During SCI, prolonged ER stress without the cellular protective mechanisms by UPR eventually results in neural apoptosis $[8,9]$. Several apoptosis mediators are implicated in ER stress-associated cell death, such as glucose-regulated protein 78 (GRP78), the transcription activation of the C/EBP homologous transcription factor (CHOP) and the activation of ERassociated caspase-12 [10]. Accumulation of unfolded proteins in the ER lumen, inhibition of protein synthesis depletion of $\mathrm{Ca}^{2+}$ from ER stores, activation of $\mathrm{CHOP} /$ GADD153 expression and caspase-12, all these events suggest the crucial role of ER in neuronal cell apoptosis signaling after SCI $[8,11]$. Nevertheless, the latest study indicated that the deletion of the pro-apoptotic CHOP did not result in improvement of locomotor function after severe contusive spinal cord injury [12]. Although ER stress has been confirmed played important role in SCI, but the relative mechanism still need to further investigation.

Nerve growth factor (NGF) is a member of the neurotrophin family and an important regulator of neural survival, development, function and plasticity. In addition, NGF can also protect cells against oxidative stress or toxin-induced apoptosis $[13,14]$. The activation of the TrkA receptor and intracellular kinase pathways, including the phosphatidylinositol-3 kinase (PI3K)/Akt and mitogen-activated protein kinase (MAPK) pathways is involved in the neurogenesis and protective effect of NGF $[15,16]$. More recently, NGF has been demonstrated a role of promoting cell survival by counteracting apoptosis caused by ER stress $[17,18]$. It has been indicated that nerve growth factor (NGF) show neuroprotective effect and improve the recovery of SCI $[19,20]$. However, the molecular mechanism of NGF treatment in the recovery of SCI still undefined completely, especially the relations of ER stress-induced apoptosis and the NGF therapeutic effect in SCI has not been investigated clearly. The precise molecular mechanisms by which ER stress leads to cell survival/death remains enigmatic, with multiple potential participants described above, but little clarity about which specific death effectors dominate particularly in SCI, especially the mechanism and effective pathway in the treatment with exogenous neurotrophic factors.

In this study, we investigated the effect of exogenous NGF and the involvement of ER stress in a regional and time-dependent manner following clip compressioninduce SCI. Our results indicated that the ER stressinduced apoptosis with the activation of CHOP, GRP78 and caspase-12 was involved in the early stage of SCI. NGF administration improved the locomotor function of SCI model rats, increased the neurons survival. The protective effect of NGF is related to the inhibition of ER stress-induced apoptosis, decreased the levels of CHOP, GRP78 and caspase-12, which also increased the expression of growth-associated protein 43 (GAP43). These results may certainly help in understanding the basic events involved in ER stress-mediated cell survival/death signaling pathways and the molecular mechanism in the recovery of SCI and other central nerve system diseases, which also contributes to the translational research of NGF in drug development.

\section{Materials and methods}

\section{Cell culture and viability assay}

PC12 cells were purchased from the Cell Storage Center of Wuhan University (Wuhan, China). PC12 Cells were cultured in Dulbecco's Modified Eagle Medium (DMEM, Invitrogen, Carlsbad, CA) supplemented with heatinactivated $10 \%$ fetal bovine serum (FBS, Invitrogen, Carlsbad, CA), 5\% horse serum, and antibiotics (100 units $/ \mathrm{ml}$ penicillin, $100 \mu \mathrm{g} / \mathrm{ml}$ streptomycin), incubated in a humidified atmosphere containing $5 \% \mathrm{CO}_{2}$ at $37^{\circ} \mathrm{C}$. PC12 cells were seeded on 96-well plates $\left(5 \times 10^{3}\right.$ cells/ well) and treated with different concentrations of ER stress activator, various doses of thapsigargin (TG, 0 , $1 \mu \mathrm{M}, 2.5 \mu \mathrm{M}, 5 \mu \mathrm{M}, 10 \mu \mathrm{M})$ for $24 \mathrm{~h}$. For determining the effect of NGF, 100ng/ml NGF was added $2 \mathrm{~h}$ prior to the addition of TG [21]. Cell viability was determined by MTT assays. $20 \mu \mathrm{l}$ MTT (3-(4,5-dimethylthiazol-2-yl)-2, 5-diphe-nyltetrazolium bromide $(5 \mathrm{mg} / \mathrm{ml}$ in PBS) was add to the cells for $4 \mathrm{~h}$. Cells were washed with PBS (pH 7.4), and $150 \mu \mathrm{l}$ DMSO was added to solubilize the formazan crystals. Fluorescence intensity was measured at 
$570 \mathrm{~nm}$. Optimal conditions of $5 \mu \mathrm{M}$ TG and $100 \mathrm{ng} / \mathrm{ml}$ NGF were used for the subsequent experiments.

To further evaluate the effect of PI3K/Akt and ERK1/2 activation on oxidative injury, cells were pretreated with specific inhibitors LY294002 $(20 \mu \mathrm{M})$ and PD98059 (20 $\mu \mathrm{M}) 2 \mathrm{~h}$ before the addition of NGF as described previously [22]. Then analyze Cell signaling and cell survival. Pretreatment compounds were not removed from the media before successive treatment conditions. All experiments were performed in triplicate.

\section{Spinal cord injury and NGF administration}

Young adult female Sprague-Dawley rats aged 8 weeks (220-250g) were purchased from Animal Center of Chinese Academy of Sciences, Shanghai, China. Animals were maintained for at least $7 \mathrm{~d}$ before the experiment in a temperature-regulated room $\left(23^{\circ} \mathrm{C}-25^{\circ} \mathrm{C}\right)$ on a 12 -h light/dark cycle and free to water and food. The protocol of the animal using and caring was conformed to Guide for the Care and Use of Laboratory Animals from National Institutes of Health and approved by the experimental procedures were approved by the Animal Care and Use Committee of Wenzhou Medical College. Animals were anaesthetized by an intraperitoneal injection of $10 \%$ chloralic hydras $(3.5 \mathrm{ml} / \mathrm{kg})$. Then rats were positioned on a cork platform. The skin was incised along the midline of back, and the vertebral column was exposed and a laminectomy was done at $\mathrm{T} 9$ vertebrae and moderate contusion injuries were performed using a vascular clip ( $2 \mathrm{~min}, 30 \mathrm{~g}$ forces, Oscar, China). Control group animals received the same surgical procedures, but impaction was not applied to the spinal cord. Postoperative care involved manual urinary bladder empty twice daily until they return of bladder function and administration of cefazolin sodium (50 mg/kg, i.p.).

NGF was purchased from Sigma (Sigma-Aldrich, St. Louis, MO, USA). The stock solution was diluted with $0.9 \% \mathrm{NaCl}$ and administered intravenously at a dose of $20 \mu \mathrm{g} / \mathrm{kg} /$ day after $30 \mathrm{~min}$ of SCI and then once per day until they were executed. Control groups were received equivolumetric administration of $\mathrm{NaCl}$ at the corresponding times. Following treatment with either vehicle or NGF, animals were treated uniformly until the final analysis of the data. All experimental animals were received daily rehabilitation procedures, including passive mobilization of hind legs twice daily. Subsequently, the rats were executed at $1,3,7$ and $14 \mathrm{~d}$.

\section{Behavioral tests}

In order to examine the locomotor function after injury, behavioral analyses were performed by trained investigators who were blind to the experimental conditions. Using the 21-point BBB locomotion scale, inclined plane test and footprint as described elsewhere [23] to evaluate open-field locomotion. BBB is a 22-point scale (scores 021 ) that systematically and logically follows recovery of hindlimb function from a score of 0 , indicative of no observed hindlimb movements, to a score of 21 , representative of a normal ambulating rodent.

The inclined plane test was performed via a testing apparatus [24]. The maximum angle at which a rat could retain its position for $5 \mathrm{sec}$ without falling was recorded for each position, and averaged to obtain a single score for each animal. Footprint analysis was performed through dip the animal's hindpaws with blue dye as described elsewhere [25]. The animal was allowed to walk across a narrow box ( $1 \mathrm{~m}$ long and $7 \mathrm{~cm}$ wide). The footprints were scanned, and digitized images were analyzed.

\section{Immunohistochemistry and histology}

Sham and SCI rats $(n=6)$ were deeply re-anesthetized with $10 \%$ chloralic hydras $(3.5 \mathrm{ml} / \mathrm{kg}$, i.p.), and perfused with $0.9 \% \mathrm{NaCl}$, followed by $4 \%$ paraformaldehyde in $0.01 \mathrm{M}$ phosphate buffered saline (PBS, $\mathrm{PH}=7.4$ ) at 1,3 , 7 and $14 \mathrm{~d}$. A T7-T9 spinal cord segment around the lesion epicenter was removed, post-fixed in cold $4 \%$ paraformaldehyde overnight, and embedded in paraffin. Transverse paraffin sections ( $5 \mu \mathrm{m}$ thickness) were mounted in Poly-L-Lysine-coated slides for histopathological examination. The lesion epicenter stained with hematoxylin and eosin for HE staining. One stained with Cresyl Violet for Nissl stain following the instruction. Consecutive slides were immunostained. The slide were incubated in $3 \% \mathrm{H}_{2} \mathrm{O}_{2}$ for $15 \mathrm{~min}$ and $80 \%$ carbinol for $30 \mathrm{~min}$ and then in blocking solution for $1 \mathrm{~h}$ at room temperature. Subsequently, the sections were incubated at $4{ }^{\circ} \mathrm{C}$ overnight with the following primary antibodies: $\mathrm{CHOP}$ (1:150), GRP78 (1:200), and caspase-12 (1:2000, Santa Cruz Biotech, CA, USA). After triple washing in PBS, the sections were incubated with horseradish peroxidaseconjugated secondary antibodies for $2 \mathrm{~h}$ at $37^{\circ} \mathrm{C}$. The reaction was stopped with 3, 3-diaminobenzidine (DAB). The results were imaged at a magnification of 400 using a Nikon ECLPSE 80i (Nikon, Japan). The optical densities and positive neuron numbers of CHOP, GRP78 and caspase- 12 were counted at 5 randomly selected fields per sample in spinal anterior horn and quantification by Imagepro-Plus. Histology and immunohistochemistry for each marker were performed simultaneously in all spinal cord samples as well as negative controls without primary antibodies.

\section{Western blot analysis}

For the in vivo protein analysis, a spinal cord segment $(0.5 \mathrm{~cm}$ length $)$ at the contusion epicenter was dissected at $1,3,7$ and $14 \mathrm{~d}$ and soon stored at $-80^{\circ} \mathrm{C}$ for western blotting. For protein extraction, the tissue was homogenized in modified RIPA buffer (50 mM Tris- $\mathrm{HCl}, 1 \%$ 
NP-40, 20 mM DTT, $150 \mathrm{mM} \mathrm{NaCl}, \mathrm{PH}=7.4)$ containing protease inhibitor cocktail $(10 \mu \mathrm{l} / \mathrm{ml}$, GE Healthcare Biosciences, PA, USA). The complex was then centrifuged at $12,000 \mathrm{rpm}$ and the supernatant obtained for protein assay. For ER stress model In vitro, PC12 cells were lysed in RIPA buffer (25 mM Tris- $\mathrm{HCl}, 150 \mathrm{mM}$ $\mathrm{NaCl}, 1 \%$ Nonidet P-40, 1\% sodium deoxycholate, and $0.1 \%$ SDS) with protease and phosphatase inhibitors. The extracts above were quantified with bicinchoninic acid (BCA) reagents (Thermo, Rockford, IL, USA). We separated proteins $(50 \mu \mathrm{g})$ on a $11.5 \%$ gel and transferred tem onto PVDF membrane (Bio-Rad, Hercules, CA, USA). The membrane was blocked with $5 \%$ milk (BioRad) in TBS with $0.05 \%$ tween 20 for 1 h and incubated with the antibodies: CHOP (1:300, Santa Cruz Biotechnology, CA, USA), GRP78 (1:300, Santa Cruz Biotechnology), caspase-12 (1:1000, Santa Cruz Biotechnology), caspase-3 (1:1000, Santa Cruz Biotechnology) in 5\% milk in TBS with $0.05 \%$ tween 20 overnight. The membranes were washed with TBS for 3 times and treated with horseradish peroxidase-conjugated secondary antibodies for $1 \mathrm{~h}$ at room temperature. Signals were visualized by ChemiDicTM XRS + Imaging System (Bio-Rad), and band uensities were quantified with Multi Gauge Software of Science Lab 2006 (FUJIFILM Corporation, Tokyo, Japan). We analyzed relative densities of the bands with Quantity One (version 4.5.2; Bio-Rad). Quantities of band densities were normalized using GAPDH.

\section{Apoptosis assay}

DNA fragmentation in vivo was detected by one step TUNEL Apoptosis Asssy KIT (Roche, Mannheim, Germany). Transverse paraffin sections $(5 \mu \mathrm{m}$ thickness) were deparaffinized and rehydrated. Sections were treated with $10 \mu \mathrm{g} / \mathrm{mL}$ proteinase $\mathrm{K}$ at $37^{\circ} \mathrm{C}$ for $30 \mathrm{~min}$, then incubated with $50 \mu \mathrm{L}$ of TUNEL inspection fluid for 60 min before rinsed three times with PBS. Images were taken at $\times 400$, using $488 \mathrm{~nm}$ wavelengths light for excitation and $530 \mathrm{~nm}$ for emission. Images were captured with a Nikon ECLIPSE Ti microscope (Nikon, Japan).

The apoptotic rates of the PC-12 cells treated with TG and NGF were measured using a PI/Annexin V-FITC kit (Invitrogen, Carlsbad, CA, USA), then analyzed by FACScan flow cytometer (Becton Dickinson, Franklin Lakes, NJ, USA) as the manual description.

\section{Immunofluorescence staining}

The sections were incubated with $10 \%$ normal donkey serum for $1 \mathrm{~h}$ at room temperature in PBS containing $0.1 \%$ Triton $\mathrm{X}-100$, followed by incubation with appropriate primary antibodies overnight at $4^{\circ} \mathrm{C}$ in the same buffer. The nuclears were stained with Hoechst 33258 $(0.25 \mu \mathrm{g} / \mathrm{ml})$ dye. For neurons and GAP43 detection, the following primary antibodies were used based on different targets: anti-NeuN (1:500, Millipore), anti-GAP43 (1:50, Santa Cruz, Biotechnology, Santa Cruz, CA). After primary antibody incubation, sections were washed for $4 \times 10$ min at room temperature, followed by incubation with Alexa Fluor594/647 donkey anti-mouse/rabbit, Alexa-Fluor488/ 594 donkey anti-rabbit/mouse, or Alexa-Fluor488/594 donkey anti-goat secondary antibody (1:500; Invitrogen Corporation, Carlsbad, CA, USA) for $1 \mathrm{~h}$ at room temperature. Sections were then washed with PBS containing 0.1\% Triton X-100 for $4 \times 10 \mathrm{~min}$, followed by $3 \times 5 \mathrm{~min}$ with PBS and briefly with water. All images were captured on Nikon ECLIPSE Ti microscope (Nikon, Tokyo, Japan).

\section{Statistical analysis}

Data were expressed as mean \pm SEM. Statistical significance was determined with Student's t-test when there were two experimental groups. For more than two groups, statistical evaluation of the data was performed using One-way Analysis-of-variance (ANOVA) test, followed by Dunnett's post hoc test with the values $P<0.05$ considered significant.

\section{Results}

ER stress-induced apoptosis is involved in the early stage of $\mathrm{SCl}$ model in vivo

In order to evaluate the role of ER stress in SCI, we performed the SCI models as described above [26]. After SCI, animals showed dramatic and bilateral hind limb paralysis with no movement at all or only slight movements of a joint from the first hours post-injury when observed during open-field walking. Then treated with NGF at three dose $(5,10,20 \mu \mathrm{g} / \mathrm{kg})$ beginning $1 \mathrm{~d}$ after injury and then once daily for 14 consecutive days. Functional recovery was then evaluated for 2 weeks after injury using the BBB rating scale [23], inclined plane test [24], and footprint recordings [25]. We scored animal locomotor activity according to the BBB scale 1d after $\mathrm{SCI}$, and the BBB scores showed that rats with SCI could no longer move (score 0 to 1 ) while the sham-operated rats walked normally (score 21). There were significant differences between both groups $(P<0.0001$; Figure $1 \mathrm{~B})$. The locomotor function increased progressively during the experimental period. At $3 \mathrm{~d}$ and $7 \mathrm{~d}$ after contusion, the BBB scores were $3.67 \pm 0.88(P<0.0001)$ and $8.00 \pm$ $0.58(P<0.0001)$. Until $14 \mathrm{~d}$ after injury, the BBB scores were achieve $12 \pm 0.88$, which corresponds to slight step placement with weight support (Figure 1B).

The lesion center was characterized by the destruction of gray and white matter. The neurons in the spinal cord of the sham-operated group had normal morphology, with a clear cytoplasm, and uniform and clear nuclei. Compared with the sham operation group (1 d posttrauma), the gray matter of the SCI group exhibited large hemorrhages. The motor neurons in the anterior 


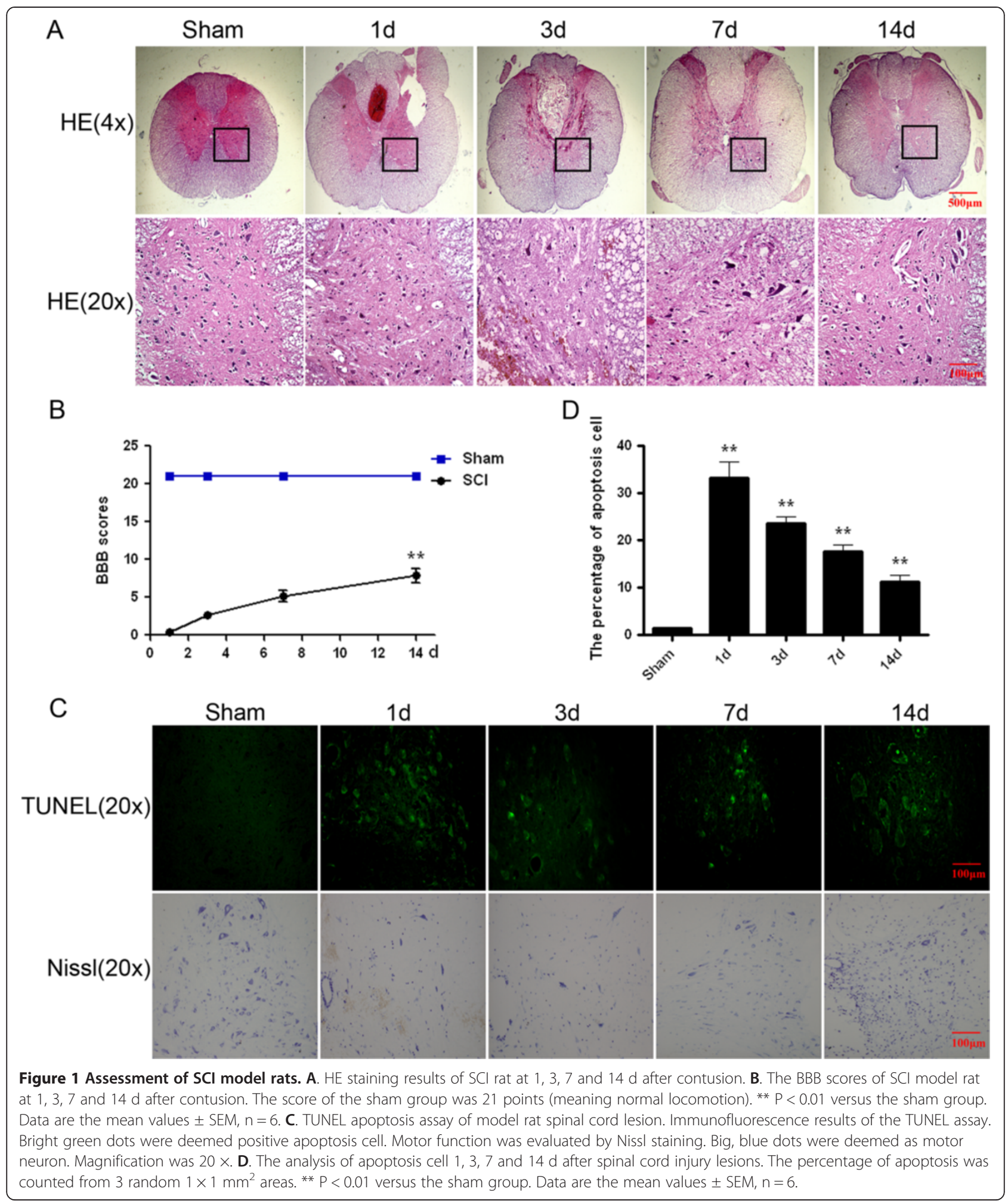

horn were shrunken or had pale homogenous cytoplasm compared with the sham group, consistent with ischemic change. Progressive destruction of the dorsal white matter and central gray matter tissue was found $3 \mathrm{~d}$ post- injury. The lesion segments displayed hemorrhagic necrosis, neuron loss, karyopyknosis, and infiltrated polymorphonuclear leukocytes and macrophages. In the segments collected $7 \mathrm{~d}$ post-injury and $14 \mathrm{~d}$ post-injury, 
there was minimal hemorrhaging and some neuron regeneration, but demyelination appeared as well as numerous cavities (Figure 1A). The cell apoptosis in the spinal lesions were detected by TUNEL staining and the bright green dots were deemed as TUNEL-positive cells in the lesions. Sham group showed no apoptosis positive cells. The numbers of TUNEL-positive cells increased significantly $1 \mathrm{~d}$ after injury and were maximal at $3 \mathrm{~d}$, then decreasing gradually (Figure $1 \mathrm{C}, \mathrm{D}$ ). The effect of $\mathrm{SCI}$ on the number of motor neurons in the spinal cord was investigated by Nissl staining. As shown in Figure 1C, SCI rat showed an extensive loss of large anterior horn cells at $1 \mathrm{~d}$ and $3 \mathrm{~d}$. In contrast, motor neurons were increased in the anterior horns at $7 \mathrm{~d}$. At $14 \mathrm{~d}$ group compared with sham group, motor neurons were remarkably preserved in the anterior horns.

We next investigate the molecular mechanism of ER stress-induced apoptosis in the SCI, immunohisochemistry staining was applied firstly. It was found that GRP78, CHOP, caspase- 12 positive cells were expressed in both gray matter and white matter, and the staining was more intense in the gray than white matter (Figure 2A). The numbers of CHOP, GRP78, caspase-12 positive cells and optical density increased significantly, and were all maximal at $3 \mathrm{~d}$ (Figure 2A, B). Thereafter, the number of positive cells and optical density gradually reduced but were still observed after $7 \mathrm{~d}$ contusion (Figure 2A, B). Until the 14d after injury, CHOP, GRP78, caspase-12 positive cells next to normal.

\section{NGF increases the survival of neurons and improves the recovery of $\mathrm{SCl}$}

To evaluate the therapeutic effect of NGF on SCI, model rats were treated with NGF by tail intravenous injection. To determine the dosage of NGF firstly, three dosage of NGF $(5,10$ and $20 \mu \mathrm{g} / \mathrm{kg} / \mathrm{d})$ was used for administration. As show in BBB scores (Figure 3A) and the inclined plane test (Figure $3 \mathrm{~B}$ ), the protective effect of NGF reached a maximum at $20 \mu \mathrm{g} / \mathrm{kg} / \mathrm{d}$. The BBB locomotor rating scores of SCI group were assessed at 1, 3, 7 and $14 \mathrm{~d}$ post-surgery. The hindlimbs were paralyzed immediately after injury, and the rats recovered extensive

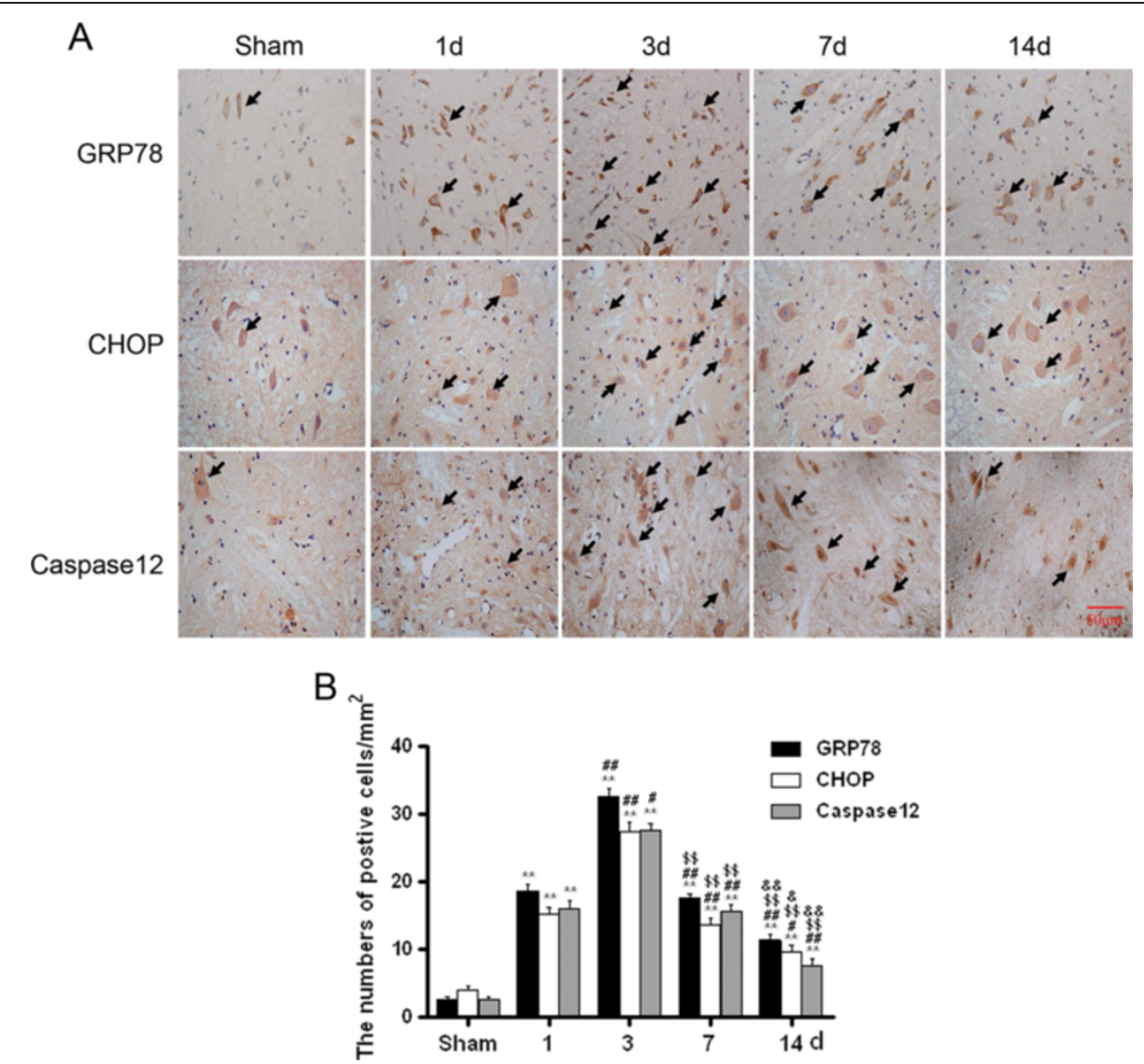

Figure 2 ER stress-induced apoptosis was involved in the early stage of SCI. A. Immunohistochemistry for GRP78, CHOP and caspase-12 in sham, 1, 3, 7 and $14 \mathrm{~d}$ after spinal cord injury lesions groups. B. Analysis of the positive cells of the immunohistochemistry results. ${ }^{*}$ represents $P<0.05$ versus the sham group, ${ }^{* *} P<0.01$ versus the sham group, ${ }^{\#} P<0.05$ versus the $1 d$ group, and ${ }^{\$} P<0.05$ versus the $3 d$ group, \& $P<0.05$ versus the $7 \mathrm{~d}$ group. Data are the mean values $\pm S E M, n=6$. 

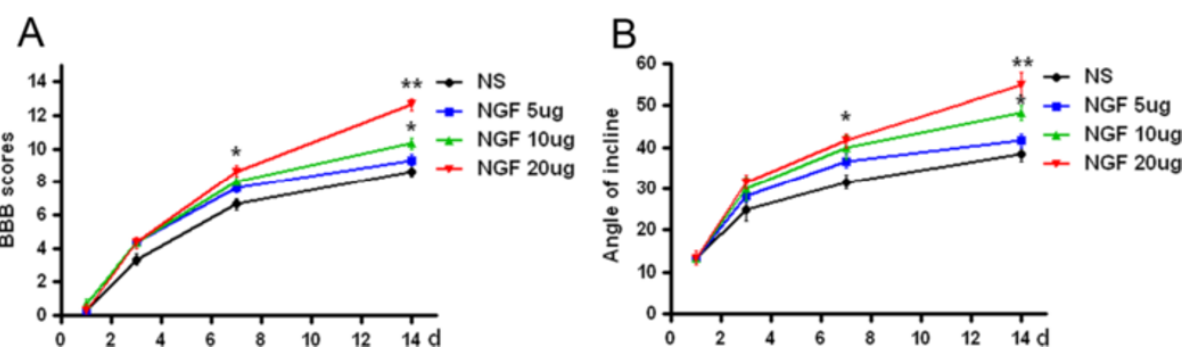

Figure 3 BBB scores and inclined plane test of different concentration of NGF treated model rats. A. BBB scores and B. inclined plane test after spinal cord injury. ${ }^{*} \mathrm{P}<0.05$ versus sham group, ${ }^{* *} \mathrm{P}<0.01$ versus sham group.

movement of hindlimbs within 7-14 days after injury. NGF treatment after injury significantly increased the hindlimb locomotor function, as assessed by BBB scores (Figure 4A). We previously discovered that nerve growth factor (NGF) reduced the SCI. As shown in Figure 4, NGF improve the BBB locomotor function compared to the SCI group at $7 \mathrm{~d}(\mathrm{P}=0.0132)$, and the effects become obviously at $14 \mathrm{~d}$ after contusion $(\mathrm{P}=0.0011)$. At $14 \mathrm{~d}$ after injury, the $20 \mu \mathrm{g} / \mathrm{ml}$ NGF group reached at $11.67 \pm 0.33$, while the control group at $8.667 \pm 0.33$.

The angle of incline, determined 2 weeks after injury, was also significantly higher in NGF treated rats compared with the vehicle control group $(P<0.01$, Figure $4 \mathrm{~B})$. As shown in Figure 4C, footprint analyses for NGF treated rats at $14 \mathrm{~d}$ after SCI disclosed fairly consistent hindlimb coordination and very little toe dragging. These findings were comparable to those in the sham control animals. By contrast, the footprints obtained from vehicle-treated animals showed inconsistent coordination and extensive drags as revealed by ink streaks extending from both hindlimbs (Figure 4C).

HE staining results of the spinal cord samples from different groups were shown in Figure 5A. Compared with sham operation group, progressive destroy of the dorsal white matter and central gray matter tissue were found in the $7 \mathrm{~d}$ SCI group. Compared with the SCI group, NGF treatment showed significant protective effect with less necrosis, karyopyknosis, infiltrated polymorphonuclear leukocytes and macrophages. The effect of NGF on the number of motor neurons in the spinal cord was also investigated. As shown in Figure 5B, the vehicle control group showed an extensive loss of large anterior horn cells. In contrast, motor neurons were remarkably preserved in the anterior horns in rats treated
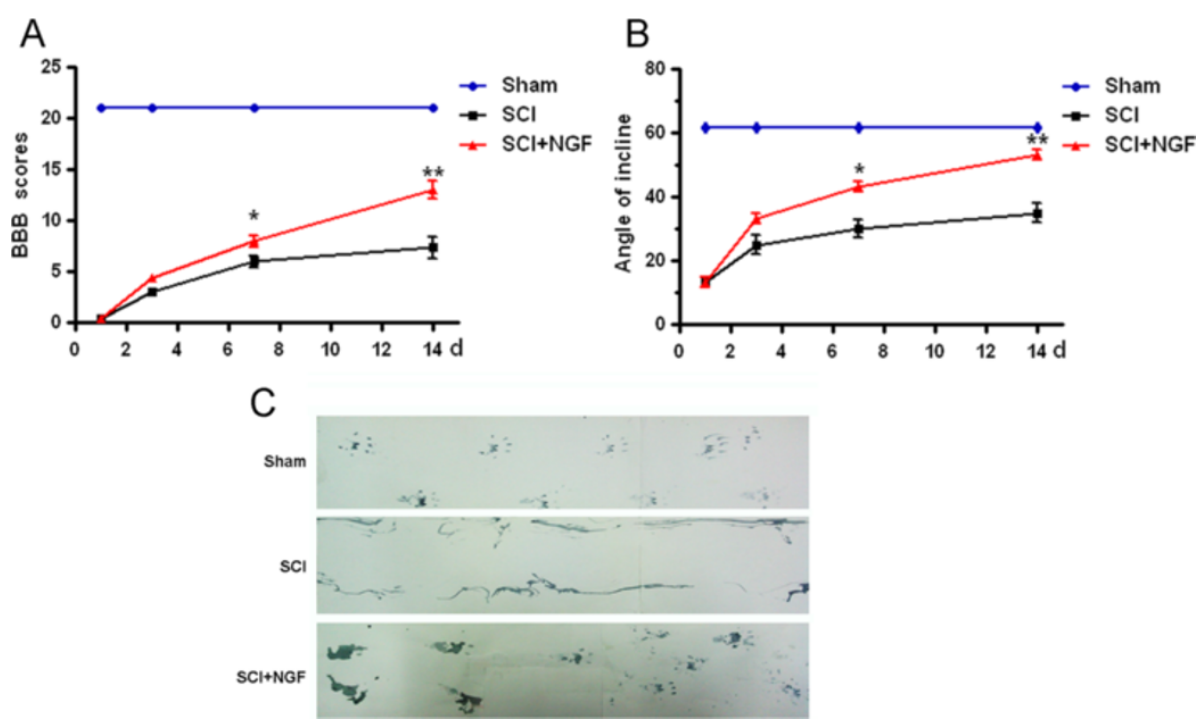

Figure 4 NGF improves the locomotor activity of SCI rats. A. The BBB scores and $\mathbf{B}$. incline plane test of sham, $\mathrm{SCl}$ group and $\mathrm{SCl}$ rat treated with NGF group. ${ }^{*} \mathrm{P}<0.05$ versus the $\mathrm{SCl}$ group, and ${ }^{* *} \mathrm{P}<0.01$ versus the $\mathrm{SCl}$ group, $\mathrm{n}=6$. $\mathbf{C}$. Representative footprints obtained from each group at 14 days after SCl show that NGF treated rats display fairly consistent weight-support plantar stepping and very little toe dragging. In contrast, vehicle control rats show consistent dorsal stepping and extensive toe dragging. 


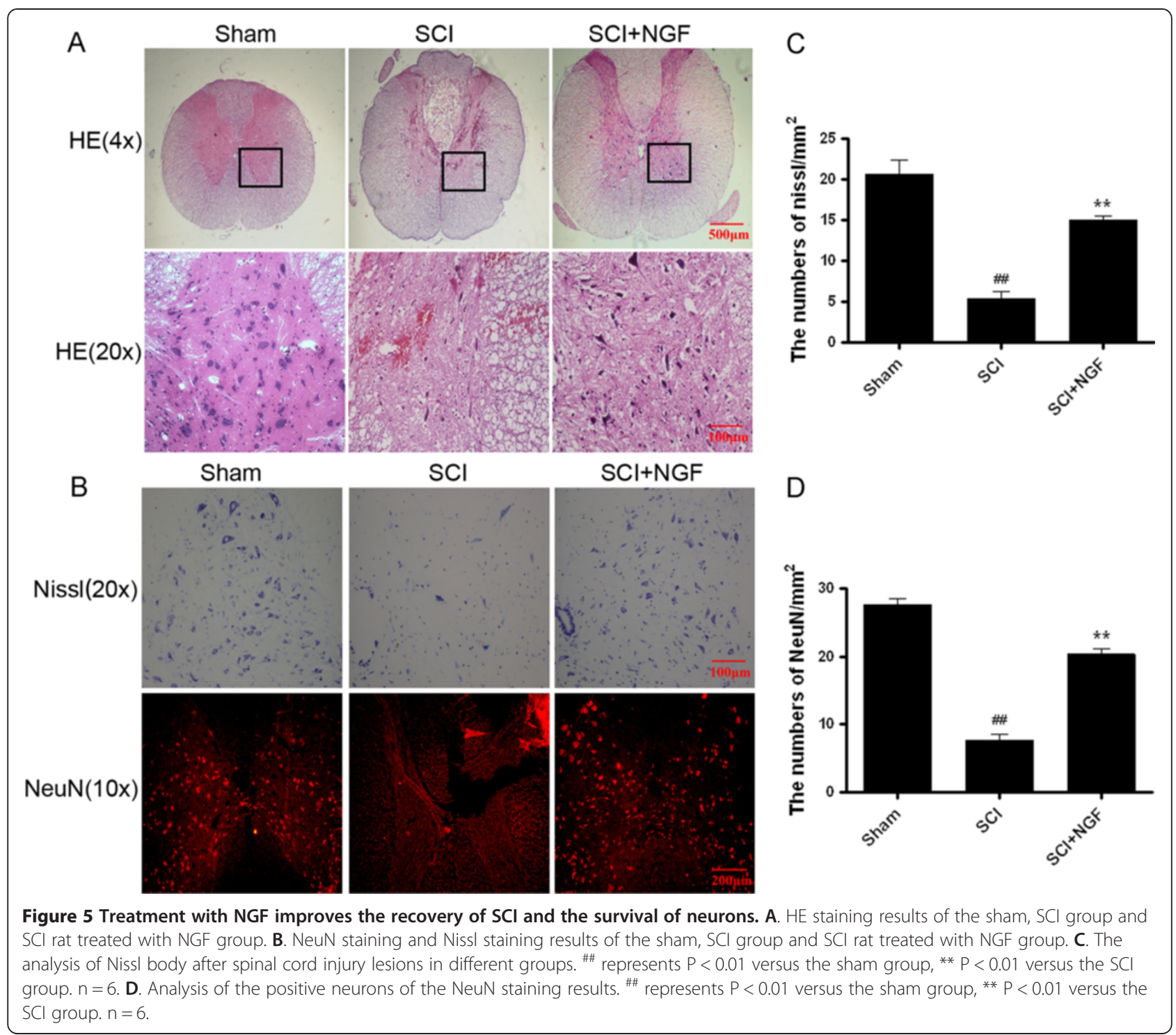

with NGF $(20 \mu \mathrm{g} / \mathrm{kg} / \mathrm{d})$ compared with vehicle control rats. No significant difference was observed in rats between sham group and NGF group.

To further confirm the protective effect of NGF, we investigated the survival of neurons directly by immunofluorecence staining. As shown in Figure 5B, spinal cord neurons in both of the white and gray matter tissue were marked by neuronal marker NeuN. The positive staining cells decreased significantly after SCI at $7 \mathrm{~d}$, and increased by NGF treatment $(P<0.0001)$. All of these data indicated that NGF administration shown protective effect on neuronal cells and improved the recovery of SCI significantly.

\section{NGF inhibits ER stress induced apoptosis and} up-regulates the neuroprotective factors

To illustrate whether the molecular mechanism of NGF is related to the regulation of ER stress, the protein expression of ER stress-induced apoptosis were detected by immunohistochemistry staining and Western blot. As shown in Figure 6A and Figure 6B, ER stress-induced apoptosis proteins (CHOP, GRP78 and caspase-12) positive cells and optical density gradually reduced by NGF administration after $7 \mathrm{~d}$ contusion. The protein expression was also detected by Western blot, it was found that the levels of CHOP, GRP78 and caspase-12 protein decreased by the treatment of NGF, compared with the SCI group after $7 \mathrm{~d}$ contusion (Figure 6D, E). Until 14 days, the positive cells and protein expression all tend to normal level.

The protein GAP43 is expressed in developing and regenerating neurons which is often used to score the condition of neural regeneration. The levels of GAP43 were detected by immunofluorecence staining, it was found that the positive red fluorescence signal in the cytoplasm 

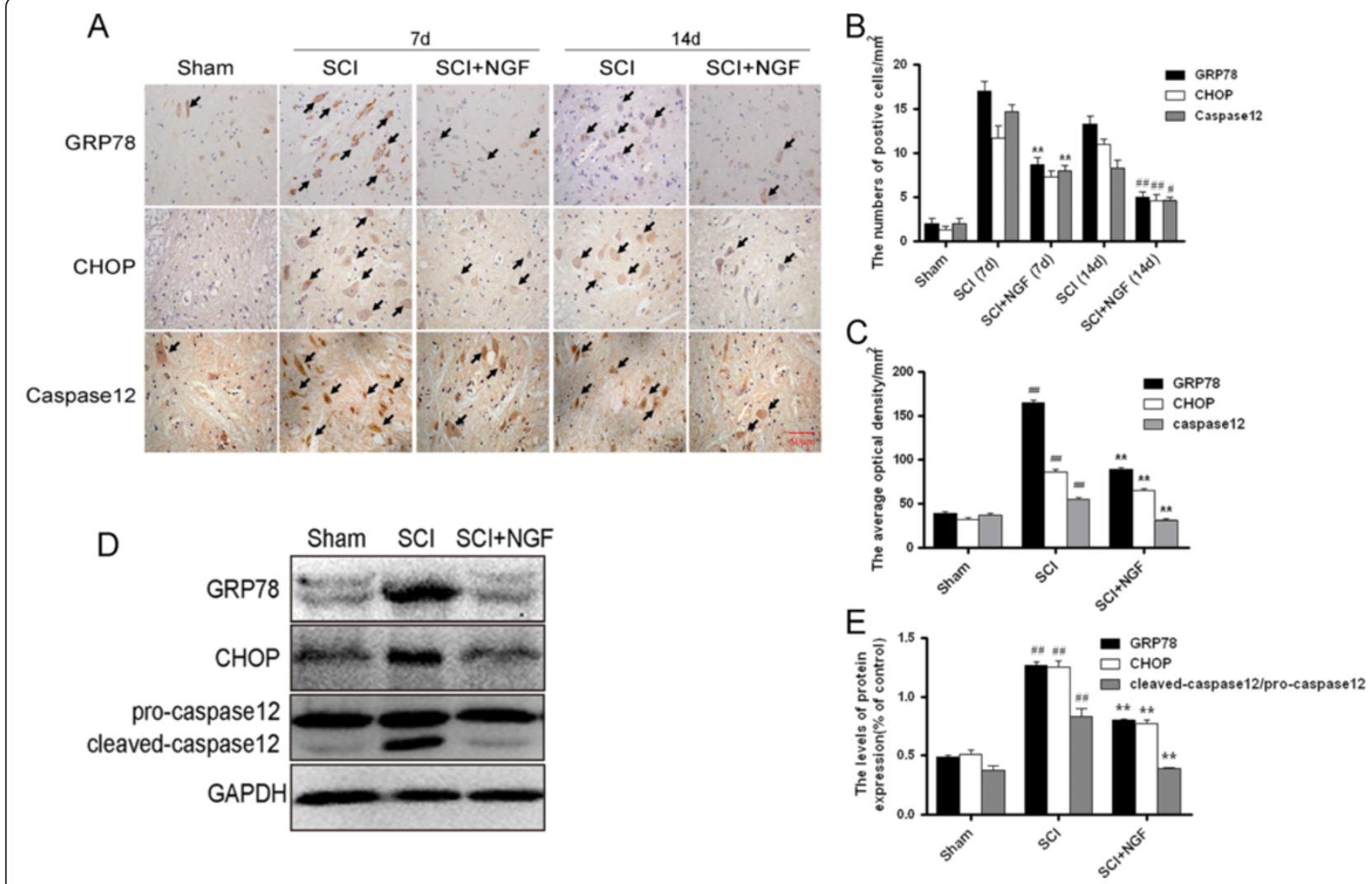

Figure 6 NGF administration inhibits the expressions of ER stress-induced apoptosis response proteins, GRP78, CHOP and caspase-12. A. Immunohistochemistry for GRP78, CHOP and caspase-12 in the sham, $7 \mathrm{~d}$ and $14 \mathrm{~d}$ after spinal cord injury lesion and NGF treatment $7 \mathrm{~d}$ and $14 \mathrm{~d}$ after injury groups. B. Analysis of the positive cells and $\mathbf{C}$. optical density of the immunohistochemistry results. ${ }^{* *} \mathrm{P}<0.01$ versus the SCl $(7 \mathrm{~d})$ group, " represents $\mathrm{P}<0.05$ versus the $\mathrm{SCI}(14 \mathrm{~d})$ group, Data are the mean values $\pm \mathrm{SEM}, \mathrm{n}=6$. D. Protein expressions of GRP78, CHOP and caspase-12 for the sham, $\mathrm{SCl}$ and NGF treatment groups. GAPDH was used as the loading control and for band density normalization. E. The optical density analysis of GRP78, CHOP, and caspase-12 protein. ${ }^{* *} \mathrm{P}<0.01$ versus the sham group. Data are the mean values $\pm S E M, n=6$.

enhanced obviously in the NGF administration group compared with the $\mathrm{SCI}$ group at $7 \mathrm{~d}$ contusion (Figure 7A). As shown in Figure $7 \mathrm{~B}$ and $\mathrm{C}$, Western blot analysis of GAP43 protein also demonstrated that the expression of GAP43 increased in the NGF treatment group, compared with SCI group after $7 \mathrm{~d}$ contusion $(P=0.0019)$, which was consistent with the results of immunofluorecence staining analysis.

To investigate the effect of NGF on cell death after SCI, we performed TUNEL staining with sections obtained at $7 \mathrm{~d}$ after injury, the TUNEL-positive cells were obviously decreased in the NGF-treated rat compared with the vehicle-treated rat (Figure 8A). When the TUNEL-positive cells were counted, the number of TUNEL-positive cells was significantly lower in the NGF treated rats compared to the vehicle-treated rat $(P=0.0019)$ (Figure $8 \mathrm{~B})$. In the Western blot analysis, the expression of Caspase 3 protein was significantly increased in the NGF-treated rat and the vehicle-treated rat compared with in the sham controls (Figure $8 \mathrm{C}, \mathrm{D}$ ).
In addition, the activated Caspase 3 expression in the NGF-treated rat was relatively lower than that in the vehicle-treated rat.

\section{The protective role of NGF is related to the activation of} downstream signal pathways PI3K/Akt/ GSK-3 $\beta$ and ERK1/2 It has been indicated that PI3K/Akt/GSK-3 $\beta$ and ERK1/2 pathways are the main downstream signals which activated by NGF, two pathways are related to the cell survival, differentiation and migration [27,28]. We next detected whether the protective effect of NGF in the recovery of SCI also involved in the activation of these two signal pathways. Western blot analysis demonstrated that the expressions of the phosphoryations of Akt (p-Akt),

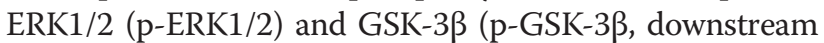
of Akt signal) decreased after SCI contusion. The decreases of phosphoryations were recovered by NGF treatment at $7 \mathrm{~d}$ (Figure 9A, B). These data indicated that both of the PI3K/Akt and ERK1/2 signals were involved in the role of NGF in the recovery of SCI. 

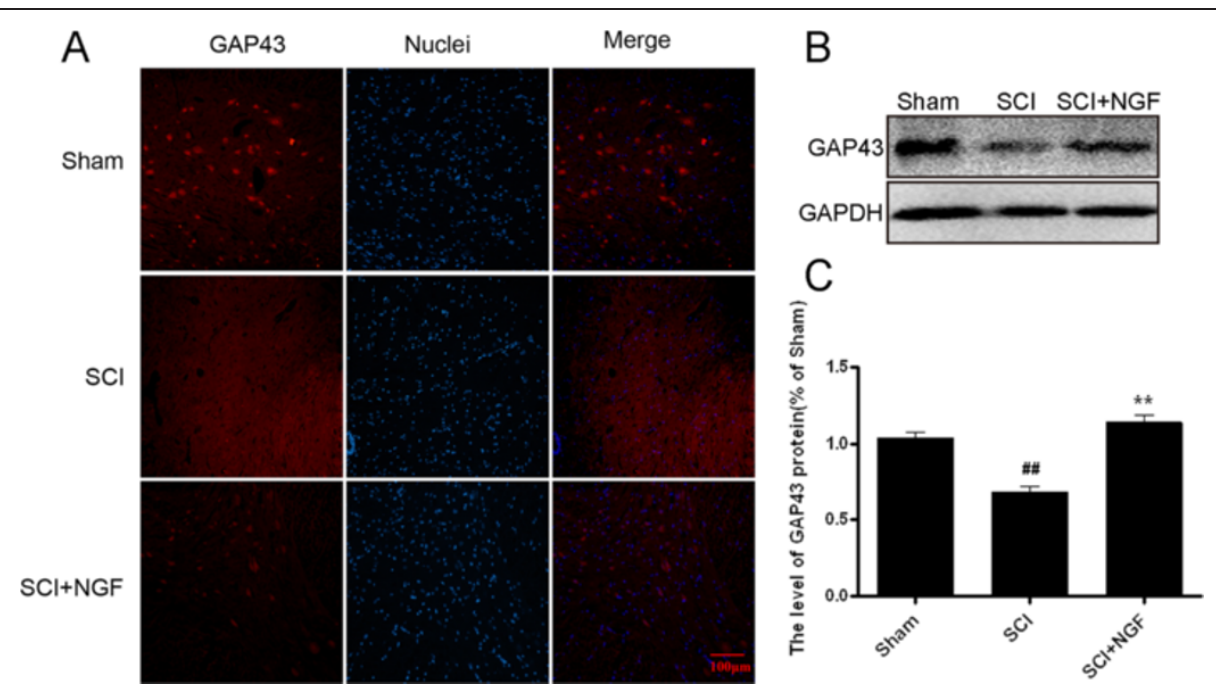

Figure 7 NGF treatment increases the level of GAP43 in spinal cord lesions. A. Immunofluorescence staining results of GAP43; the nuclear is labeled by Hoechst (blue), the neurons with obvious GAP43 signals are labeled by bright right dots, magnification was $20 \times$. B. The protein expressions of GAP43 in sham, SCl rats and SCI rats treated with NGF groups. GAPDH was used as the loading control and for band density normalization. $C$. The optical density analysis of GAP43 protein. ${ }^{*} P<0.01$ versus the $\mathrm{SCl}$ group, and ${ }^{\# \#}$ represents $\mathrm{P}<0.01$ versus the sham group. Data are the mean values \pm SEM, $n=6$.

The activation of downstream signals is crucial for the protective effect of NGF in the chronic ER stress model in vitro

To further confirm the role of NGF in the ER stressinduced apoptosis in vitro, we used ER stress activator TG treated PC-12 cells to replicate the apoptosis model. As shown in Figure $9 \mathrm{C}$ and D, cell viability decreased with the increase of TG concentration $(P=0.0019)$, combination with NGF partially increased cell viability compared with TG group $(P=0.0004)$. Cell apoptosis was analyzed by FACScan with PI/Annexin V-FITC staining, it was found that NGF inhibited the apoptosis induced by TG in PC-12 cells, compared with TG group $(P=0.0003$, Figure 9E, F).

To investigate the molecular mechanism of NGF in the ER stress-induced cell apoptosis model in vitro, two signal inhibitors LY294002 for PI3K/Akt and PD98059

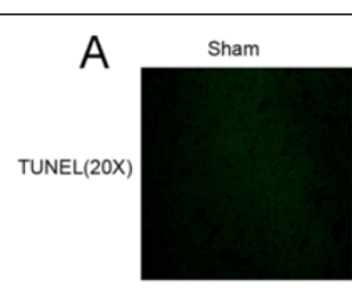

B

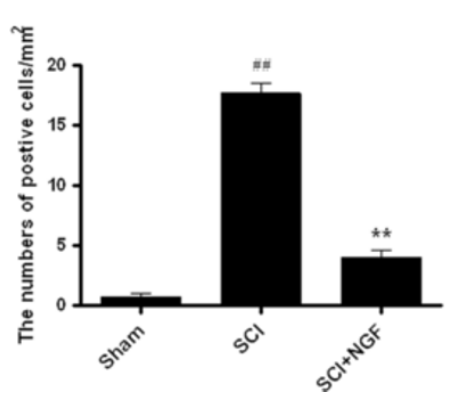

$\mathrm{SCl}$
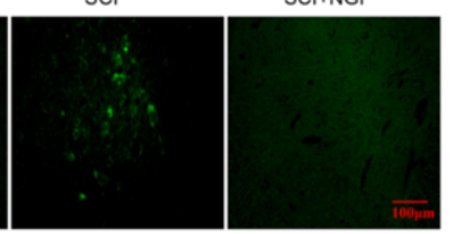

D

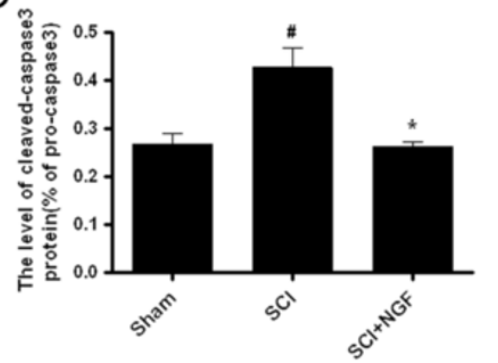

Figure 8 NGF decreases the level of apoptosis in spinal cord lesions. A. TUNEL apoptosis assay of model rat spinal cord lesions. Immunofluorescence result of the TUNEL assay. Bright green dots were deemed positive apoptosis cell, magnification was 20x. B. The analysis of apoptosis cell of the sham, SCl and NGF treatment groups. The percentage of apoptosis was counted from 3 random $1 \times 1$ mm ${ }^{2}$ areas. $\mathbf{C}$. Protein expressions of caspase-3 for the sham, SCl and NGF treatment groups. $\mathbf{D}$. The optical density analysis of caspase-3 protein. ${ }^{*} \mathrm{P}<0.05$ versus the $\mathrm{SCl}$ group, and ${ }^{\#} \mathrm{P}<0.05$ versus the sham group. ${ }^{* *} \mathrm{P}<0.01$ versus the $\mathrm{SCl}$ group, and ${ }^{\# \#} \mathrm{P}<0.01$ versus the sham group. Data are the mean values $\pm \mathrm{SEM}, \mathrm{n}=6$. 


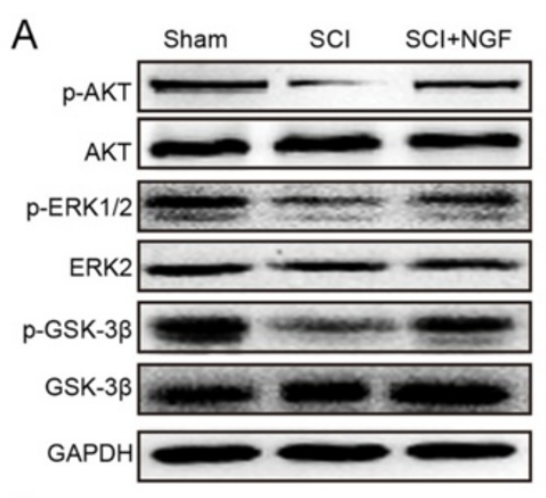

C

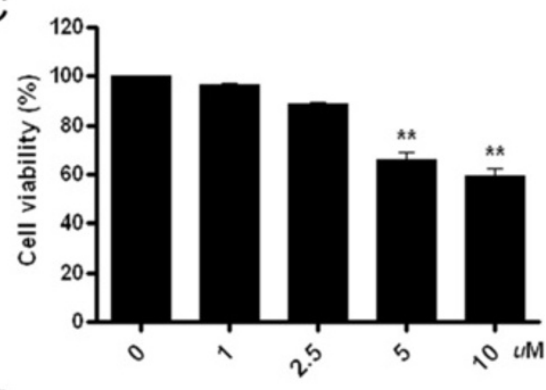

E
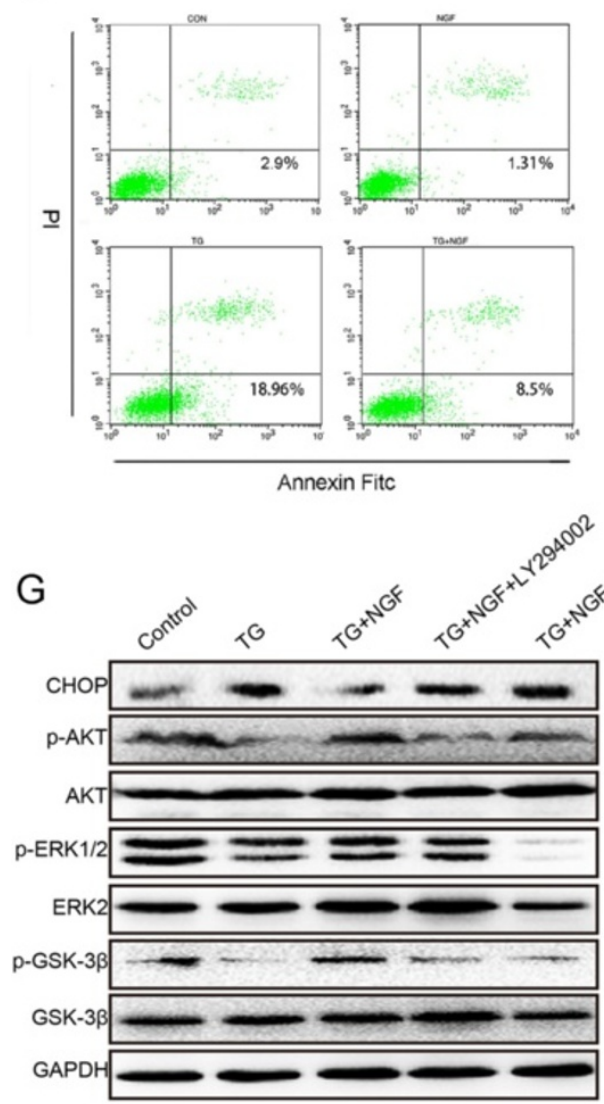

\section{B}

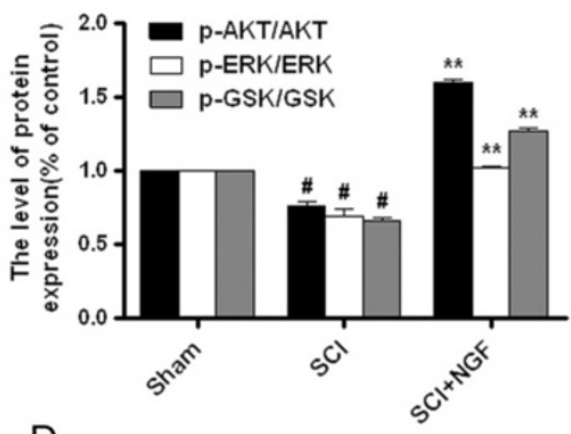

D
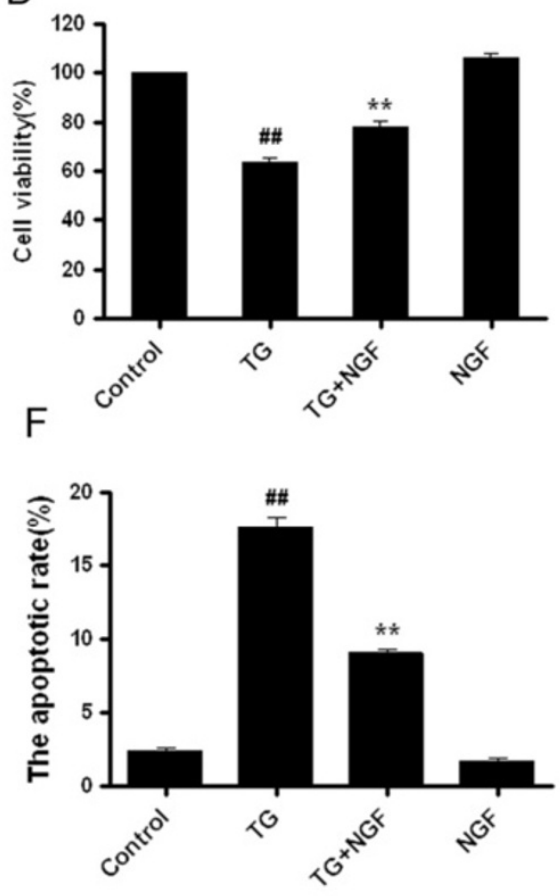

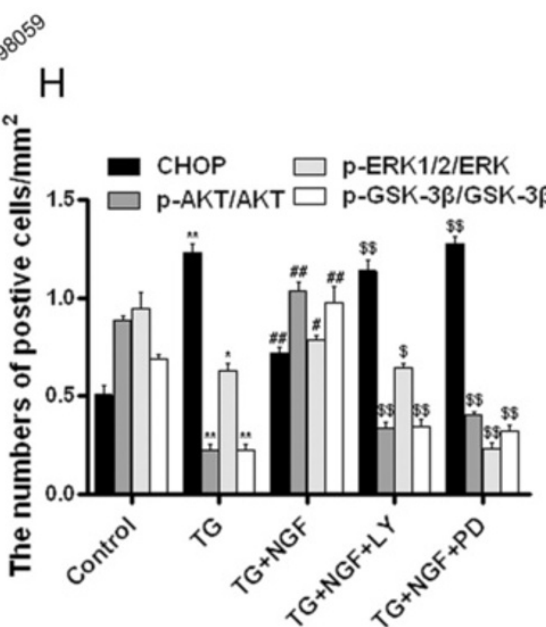

Figure 9 (See legend on next page.) 
(See figure on previous page.)

Figure $9 \mathrm{PI} K / \mathrm{Akt} / \mathrm{GSK}-3 \beta$ and ERK1/2 signals are involved in the protective effect of bFGF both in SCl rats and PC12 cells under

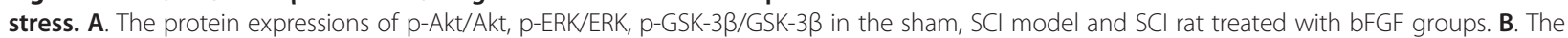

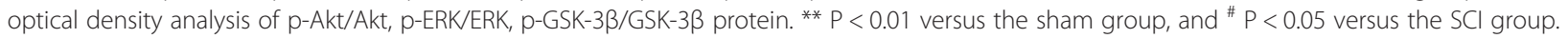
Data are the mean values $\pm S E M, n=6$. C. MTT results of the different concentrations of TG-treated PC12 cells. $\mathbf{D}$. MTT result of NGF-treated PC12 cells induced by TG. E. FACScan result of PI/Annexin V-FITC staining for cell apoptosis analysis. F. Statistical result of apoptosis rate in PC12 cells treated with TG and NGF. ${ }^{*} P<0.01$ versus the control group, and ${ }^{\#} P<0.05$ versus the TG group. Data are the mean values $\pm S E M, n=3$. G. The protein expressions of CHOP, GRP78, p-Akt, p-ERK1/2, p-GSK-3 $\beta$ in ER stress-induced apoptosis PC12 cells treated with NGF and different inhibitors. GAPDH was used as the loading control and for band density normalization. $\mathbf{H}$. The optical density analysis of CHOP, GRP78, p-Akt, p-ERK1/2 and p-GSK-3 $\beta$ protein. ${ }^{*} P<0.05$ versus the control group, ${ }^{\#}$ represents $P<0.05$ versus the TG group, ${ }^{\$} P<0.05$ versus the TG + NGF group. Data are the mean values $\pm S E M, n=6$.

for ERK1/2 were added. Both of these inhibitors have no effect on cell death when used respectively [29,30]. The activations of CHOP, p-Akt, p-ERK1/2 and p-GSK-3 $\beta$ were determined by Western blot analysis. As shown in Figure $9 \mathrm{G}$ and $\mathrm{H}$, the activation of $\mathrm{CHOP}$ by TG treatment was inhibited by NGF addition, but the protective effect of NGF was abolished by LY294002 and PD98059, the expression of CHOP increased significantly by the inhibitors combination, compared with NGF treatment group $(P=0.0049$ and $P=0.0046)$. Meanwhile, the levels of p-Akt, p-ERK1/2 and p-GSK-3 $\beta$ increased by NGF treatment and decreased by inhibitors addition. All of these data demonstrated the protective role of NGF in the ER stress-induced apoptosis is related to the activation of downstream signals PI3K/Akt and ERK1/2 both in vitro and in vivo.

\section{Discussion}

The failure of axons to regenerate following CNS trauma results from decreased intrinsic properties of the neurons [31], the most predominant features which related to the recovery of SCI are the absence of neurotrophic factors and the presence of inhibitory factors in the environment $[32,33]$. In this study, our goal was to identify the cellular and molecular changes after acute spinal cord injury and NGF treatment that improve locomotor function of model rats.

Previous studies have demonstrated a variety of crucial functions of NGF in the nervous system, which is associated with central neuronal plasticity. As a member of neurotrophic factors, NGF was discovered as a molecule that stimulates the survival and maturation of developing neurons in the peripheral nervous system and has later been shown to protect adult neurons in the degenerating mammalian brain $[34,35]$. Zhang et al demonstrated that treatment with recombinant DNA vaccine promotes functional recovery in spinal cord hemisected adult rats, associated with expression of endogeous NGF significantly upregulated [36]. Besides, latest study investigated the possible protective actions of melatonin on SCI-induced damage and urinary bladder dysfunction, reduce of NGF levels due to $\mathrm{SCI}$ were restored by melatonin treatment, suggest that melatonin reduces SCIinduced tissue injury and improves bladder functions through its effects on oxidative stress and NGF. Administration with recombinant adenovirus encoding NGF along saphe nous branch in transected femoral nerve, NGF acted as a guidance molecule to promote branch point entrance of sensory axons into the saphenous branch, significantly increased the accuracy of saphenous branch neurons reinnervation [37]. In our study, treatment with exogenous NGF increased the locomotor function progressively during the experimental period. Increased survival of neurons markedly, increased the level of GAP43 which is considered a crucial component of an effective regenerative response in the nervous system, indicated that exogenous NGF administration shown protective effect and improved the recovery of SCI.

It is well known that SCI is a process involving various self-destructive processes that occur by a variety of factors based on disturbances in ionic homeostasis, local edema, focal hemorrhage, excitotoxicity, presence of free radicals and free fatty acids [38,39]. Certain studies have indicated that neuronal and glial cell apoptosis plays a role in SCI and that the inhibition of neuronal and oligodendroglial apoptosis may be a therapeutic strategy $[40,41]$. The results from the present study demonstrated that the pathological changes of the neurons and TUNEL-positive cells increased in the injured spinal cord, which led to neuronal and glial cell loss, and finally induced the impairment of locomotor activity according to the BBB scale. Certain studies, have suggested that the ER stress-signal may have a direct role in promoting cell death in neuronal injury diseases [42,43]. CHOP plays a critical role in ER stress-induced apoptosis, and it is believed to play a central role in ER stress-induced cell death, has been implicated in mediating neurodegeneration in animals with Alzheimer's disease [44]. CHOP activation has been observed in neurons undergoing apoptosis due to perturbations in ER calcium levels in neurotoxin model of parkinsonism in vivo [45]. Following spinal cord injury, rats deficient in CHOP signaling show increased spared white matter and enhanced locomotor recovery by 6 weeks. At 24 hours 
after SCI, ATF4 and CHOP are upregulated in under perfused microvessels. The expression increased levels of $\mathrm{CHOP}$ in the rats with $\mathrm{SCI}$ revealed that $\mathrm{CHOP}$-mediated ER stress-induced apoptosis may be involved in SCI [46]. In vitro, it has also been indicated that NGF could protect PC12 cells against ER stress induced by TG, the role of pre-treatment NGF is related to the inhibition of Bax translocation from cytosol to the mitochondria, which led to loss of mitochondrial transmembrane potential, cytochrome c release, activation of caspases and apoptosis [21]. In this study, we demonstrated that ER stressinduced apoptosis was involved in the responses of SCI, the levels of related proteins including CHOP, GRP78 and caspase- 12 protein increased obviously and decreased by treatment of NGF after $7 \mathrm{~d}$ contusion in vivo, which also been detected in PC12 cell injury models induced by TG, suggested the neuroprotective effect of NGF was related to the inhibition of chronic ER stress-induced apoptosis.

Early study has demonstrated that the role of NGF is related to tyrosine kinase $\mathrm{A}(\operatorname{Trk} \mathrm{A})$, and activation of downstream signals [47], including PI3K/Akt/GSK3ßand MEK/ERK1/2 [48-50]. Study has observed a timedependent and dose-dependent effect of NGF on the PI3K/Akt and MAPK/ERK pathways, which also been involved in the other neurothrophic factors such as basic fibroblast growth factor in our previous studies of the recovery of SCI [26]. It has reported that localized microdomains of axonal PI3K activity drive the activity of axonal F-actin patches which essential for the formation of filopodia and branches from the axon, and show that NGF increases the formation of axonal filopodia by signaling through PI3K-Akt [51]. Other latter findings are consistent with the key role of PI3K and ERK signals in sensitization of TRPV1 by NGF and may explain the previously published observation that adult, but not neonatal, rat dorsal root ganglion neurons are sensitized by NGF [52]. Besides, NGF protects dorsal root ganglion neurons from oxaliplatin by modulating JNK/Sapk and ERK1/2, the findings assess the validity of MAPKs as the target of neuroprotective therapies during chemotherapeutic treatment. Moreover they also describe a double role for ERK1/2, depending on cellular stimulation, since it mediates neuronal apoptosis after oxaliplatin exposure [53]. When a specific inhibitor of PI3K, LY294002, was added to glucose analog 2-deoxy-D-glucose plus NGFtreated PC12 cells, both the effects of NGF on 2DGinduced apoptosis and GRP78 expression were significantly diminished [19]. In our study, the protective effect of NGF was also abolished by specific inhibitors LY294002 and PD98059, confirmed that the protective role of NGF here is related to the activation of downstream signals PI3K/Akt/GSK-3 $\beta$ and ERK1/2 in ER stress-induced apoptosis. In the following study, to further confirmed the role of NGF and the relations with chronic ER stress in the recovery of SCI model, siRNA of CHOP or ATF4 should be applied, which may contributes to the evidences of NGF protection through regulation of ER stress in neuronal cell death in vivo. Even so, over the past 30 years neurotrophic factors have generated considerable excitement for their potential as therapy for a wide variety of neurological disorders, for which there is currently no treatment. NGF appeared to be efficacious in two phase II clinical trials, but failed in a large scale phase III trial, to explore the appropriate therapeutic time window and special drug delivery system combined with factors still need long-term study. It also need to be addressed that NGF is not stable enough which is easy to be degradated by various enzymes in vitro, resulting in the loss of biological activity. So the combination with other drugs or delivery systems to increase its stability and smoothly through the spinal cord barrier may contributes to the functions of NGF. While the therapeutic potential of NGF has been well-recognized for decades, attempts to translate that potential to the clinic have been disappointing, largely due to significant delivery obstacles. Moreover, the mechanism of traumatic CNS injury diseases also undefined clearly, this study lays the ground work for future translational confidence of NGF in CNS diseases, especially the relations to ER stress. Collectively, the translational application study of NGF may not only focus on the effect in the neurogenesis, the combination with special biomaterials which can improves the efficiency and prolongs the effective time should also be addressed.

In conclusion, our research demonstrated that treatment with exogenous NGF increased the survival of neurons in the spinal cord lesions and improved the functional recovery of acute spinal cord injury model rats. Inhibition of ER stress induced apoptosis and increase of neuroprotective factor GAP43 is involved in the role of NGF in the neuronal cell death both in vivo and in vitro. These data demonstrate that therapeutic strategies targeting on chronic ER stress with NGF which also plays neurotrophic effects may be suitable for the therapy of central nervous system injuries, the effective combination with special drug delivery system or other factors still need to further investigations.

\section{Competing interests}

The authors declare no conflict of interest.

\section{Authors' contributions}

$J X$ and LL conceived and designed the experiments. HYZ, FZW, XXK, JY, HJC, $L C D, Y C, L B Y$ and SPZ performed the experiments. ZGW, HXS JX analyzed the data. $X Z, X B F, H Z X$ and $X K L$ contributed reagents/materials/analysis tools. $H Y Z$, JX wrote the paper.

\section{Acknowledgments}

This work was supported by Zhejiang Provincial Program for the Cultivation of High-level Innovative Health talents (to J.X.), National Natural Science Funding of China (81372112, 81200958, 81200010, 81302775), State Key Basic 
Research Development Program (2012CB518105), Zhejiang Provincial Project of Protein Medicine Key Group (2010R50042), Ningbo City Natural Science Funding (2013A610275).

\section{Author details}

'Key Laboratory of Biotechnology and Pharmaceutical Engineering, Molecular Pharmacology Research Center, School of Pharmacy, Wenzhou Medical University, Wenzhou, Zhejiang 325035, China. ${ }^{2}$ Department of Pharmacy, Cixi People's Hospital, Cixi, Zhejiang 315300, China. ${ }^{3}$ Institute of Hypoxia Research, School of Basic Medical Sciences, Wenzhou Medical University, Wenzhou, Zhejiang 325035, China. ${ }^{4}$ Department of Orthopaedics, The Second Affiliated Hospital, Wenzhou Medical University, Wenzhou, Zhejiang 325035, China. ${ }^{5}$ Medicine Research Center, Ningbo Medical Treatment Center Lihuili Hospital, Ningbo, Zhejiang 330200, China. ${ }^{6}$ Institute of Basic Medical Sciences, Chinese PLA General Hospital, Beijing 100853, China.

Received: 16 December 2013 Accepted: 14 March 2014 Published: 15 May 2014

\section{References}

1. Penas C, Guzman MS, Verdu E, Fores J, Navarro X, Casas C: Spinal cord injury induces endoplasmic reticulum stress with different cell-type dependent response. J Neurochem 2007, 102:1242-1255.

2. Thuret S, Moon LD, Gage FH: Therapeutic interventions after spinal cord injury. Nat Rev Neurosci 2006, 7:628-643.

3. Katoh K, Ikata T, Katoh S, Hamada Y, Nakauchi K, Sano T, Niwa M: Induction and its spread of apoptosis in rat spinal cord after mechanical trauma. Neurosci Lett 1996, 216:9-12.

4. Kim I, Xu W, Reed JC: Cell death and endoplasmic reticulum stress: disease relevance and therapeutic opportunities. Nat Rev Drug Discov 2008, 7:1013-1030

5. Viana RJ, Nunes AF, Rodrigues CM: Endoplasmic reticulum enrollment in Alzheimer's disease. Mol Neurobiol 2012, 46:522-534.

6. Lynch JM, Maillet M, Vanhoutte D, Schloemer A, Sargent MA, Blair NS, Lynch KA, Okada T, Aronow BJ, Osinska H, Prywes R, Lorenz JN, Mori K, Lawler J, Robbins J, Molkentin JD: A thrombospondin-dependent pathway for a protective ER stress response. Cell 2012, 149:1257-1268.

7. Liu XD, Ko S, Xu Y, Fattah EA, Xiang Q, Jagannath C, Ishii T, Komatsu M, Eissa NT: Transient aggregation of ubiquitinated proteins is a cytosolic unfolded protein response to inflammation and endoplasmic reticulum stress. J Biol Chem 2012, 287:19687-19698.

8. Valenzuela V, Collyer E, Armentano D, Parsons GB, Court FA, Hetz C: Activation of the unfolded protein response enhances motor recovery after spinal cord injury. Cell Death Dis 2012, 3:e272.

9. Ohri SS, Maddie MA, Zhao Y, Qiu MS, Hetman M, Whittemore SR: Attenuating the endoplasmic reticulum stress response improves functional recovery after spinal cord injury. Glia 2011, 59:1489-1502.

10. Zhang Z, Tong N, Gong Y, Qiu Q, Yin L, Lv X, Wu X: Valproate protects the retina from endoplasmic reticulum stress-induced apoptosis after ischemia-reperfusion injury. Neurosci Lett 2011, 504:88-92.

11. Soboloff J, Berger SA: Sustained ER Ca2+ depletion suppresses protein synthesis and induces activation-enhanced cell death in mast cells. J Biol Chem 2002, 277:13812-13820.

12. Ohri SS, Maddie MA, Zhang Y, Shields CB, Hetman M, Whittemore SR: Deletion of the pro-apoptotic endoplasmic reticulum stress response effector CHOP does not result in improved locomotor function after severe contusive spinal cord injury. J Neurotrauma 2012, 29:579-588.

13. Salinas M, Diaz R, Abraham NG, de Galarreta CM R, Cuadrado A: Nerve growth factor protects against 6-hydroxydopamine-induced oxidative stress by increasing expression of heme oxygenase- 1 in a phosphatidylinositol 3-kinase-dependent manner. J Biol Chem 2003, 278:13898-13904.

14. Tang LL, Wang R, Tang XC: Huperzine A protects SHSY5Y neuroblastoma cells against oxidative stress damage via nerve growth factor production. Eur J Pharmacol 2005, 519:9-15.

15. Diering GH, Numata Y, Fan S, Church J, Numata M: Endosomal acidification by $\mathrm{Na}+/ \mathrm{H}+$ exchanger NHE5 regulates TrkA cell-surface targeting and NGF-induced PI3K signaling. Mol Biol Cell 2013, 24:3435-3448.

16. Yu W, Sheng M, Xu R, Yu J, Cui K, Tong J, Shi L, Ren H, Du H: Berberine protects human renal proximal tubular cells from hypoxia/reoxygenation injury via inhibiting endoplasmic reticulum and mitochondrial stress pathways. J Trans/ Med 2013, 11:24

17. Shimoke K, Amano H, Kishi S, Uchida H, Kudo M, Ikeuchi T: Nerve growth factor attenuates endoplasmic reticulum stress-mediated apoptosis via suppression of caspase-12 activity. J Biochem 2004, 135:439-446.

18. Shimoke K, Kishi S, Utsumi T, Shimamura Y, Sasaya H, Oikawa T, Uesato S, Ikeuchi T: NGF-induced phosphatidylinositol 3-kinase signaling pathway prevents thapsigargin-triggered ER stress-mediated apoptosis in PC12 cells. Neurosci Lett 2005, 389:124-128.

19. Kishi S, Shimoke K, Nakatani Y, Shimada T, Okumura N, Nagai K, Shin-Ya K, Ikeuchi T: Nerve growth factor attenuates 2-deoxy-d-glucose-triggered endoplasmic reticulum stress-mediated apoptosis via enhanced expression of GRP78. Neurosci Res 2010, 66:14-21.

20. de Oliveira MR, da Rocha RF, Stertz L, Fries GR, de Oliveira DL, Kapczinski F, Moreira JC: Total and mitochondrial nitrosative stress, decreased brain-derived neurotrophic factor (BDNF) levels and glutamate uptake, and evidence of endoplasmic reticulum stress in the hippocampus of vitamin A-treated rats. Neurochem Res 2011, 36:506-517.

21. Szegezdi E, Herbert KR, Kavanagh ET, Samali A, Gorman AM: Nerve growth factor blocks thapsigargin-induced apoptosis at the level of the mitochondrion via regulation of Bim. J Cell Mol Med 2008, 12:2482-2496.

22. Wang Z, Zhang H, Xu X, Shi H, Yu X, Wang X, Yan Y, Fu X, Hu H, Li X, Xiao J: bFGF inhibits ER stress induced by ischemic oxidative injury via activation of the PI3K/Akt and ERK1/2 pathways. Toxicol Lett 2012, 212:137-146.

23. Basso DM, Beattie MS, Bresnahan JC: A sensitive and reliable locomotor rating scale for open field testing in rats. J Neurotrauma 1995, 12:1-21.

24. Rivlin $\mathrm{AS}$, Tator $\mathrm{CH}$ : Objective clinical assessment of motor function after experimental spinal cord injury in the rat. J Neurosurg 1977, 47:577-581.

25. Stirling DP, Khodarahmi K, Liu J, McPhail LT, McBride CB, Steeves JD, Ramer MS, Tetzlaff W: Minocycline treatment reduces delayed oligodendrocyte death, attenuates axonal dieback, and improves functional outcome after spinal cord injury. J Neurosci 2004, 24:2182-2190.

26. Zhang $H Y$, Zhang $X$, Wang ZG, Shi $H X$, Wu FZ, Lin BB, Xu XL, Wang XJ, Fu $X B$, Li ZY, Shen CJ, Li XK, Xiao J: Exogenous basic fibroblast growth factor inhibits ER stress-induced apoptosis and improves recovery from spinal cord injury. CNS Neurosci Ther 2013, 19:20-29.

27. Pisanti S, Picardi P, Prota L, Proto MC, Laezza C, McGuire PG, Morbidelli L, Gazzerro P, Ziche M, Das A, Bifulco M: Genetic and pharmacologic inactivation of cannabinoid $\mathrm{CB} 1$ receptor inhibits angiogenesis. Blood 2011, 117:5541-5550.

28. Valkov A, Kilvaer TK, Sorbye SW, Donnem T, Smeland E, Bremnes RM Busund LT: The prognostic impact of Akt isoforms, PI3K and PTEN related to female steroid hormone receptors in soft tissue sarcomas. J Trans/ Med 2011, 9:200.

29. Lan A, Liao X, Mo L, Yang C, Yang Z, Wang X, Hu F, Chen P, Feng J, Zheng $D$, Xiao $L$ : Hydrogen sulfide protects against chemical hypoxia-induced injury by inhibiting ROS-activated ERK1/2 and p38MAPK signaling pathways in PC12 cells. PLoS One 2011, 6:e25921.

30. Tan Y, Ichikawa T, Li J, Si Q, Yang H, Chen X, Goldblatt CS, Meyer CJ, Li X, Cai L, Cui T: Diabetic downregulation of Nrf2 activity via ERK contributes to oxidative stress-induced insulin resistance in cardiac cells in vitro and in vivo. Diabetes 2011, 60:625-633.

31. Wu JC, Huang WC, Tsai YA, Chen YC, Cheng H: Nerve repair using acidic fibroblast growth factor in human cervical spinal cord injury: a preliminary Phase I clinical study. J Neurosurg Spine 2008, 8:208-214.

32. Markus A, Patel TD, Snider WD: Neurotrophic factors and axonal growth. Curr Opin Neurobiol 2002, 12:523-531.

33. Filbin MT: Myelin-associated inhibitors of axonal regeneration in the adult mammalian CNS. Nat Rev Neurosci 2003, 4:703-713.

34. Manni L, Rocco ML, Bianchi P, Soligo M, Guaragna M, Barbaro SP, Aloe L: Nerve growth factor: basic studies and possible therapeutic applications. Growth Factors 2013, 31:115-122.

35. Aloe L, Rocco ML, Bianchi P, Manni L: Nerve growth factor: from the early discoveries to the potential clinical use. J Trans/ Med 2012, 10:239.

36. Zhang Y, Hao CG, Hu LQ, Dong J, Wei P, Xu D, Xiao ZC, Wang TH: Recombinant DNA vaccine against inhibition of neurite outgrowth promotes functional recovery associated with endogeous NGF expression in spinal cord hemisected adult rats. Neurochem Res 2009, 34:1635-1641. 
37. Hu X, Cai J, Yang J, Smith GM: Sensory axon targeting is increased by NGF gene therapy within the lesioned adult femoral nerve. Exp Neurol 2010, 223:153-165.

38. Dumont RJ, Okonkwo DO, Verma S, Hurlbert RJ, Boulos PT, Ellegala DB, Dumont AS: Acute spinal cord injury, part l: pathophysiologic mechanisms. Clin Neuropharmacol 2001, 24:254-264.

39. Park E, Velumian AA, Fehlings MG: The role of excitotoxicity in secondary mechanisms of spinal cord injury: a review with an emphasis on the implications for white matter degeneration. J Neurotrauma 2004, 21:754-774

40. Dang AB, Tay BK, Kim HT, Nauth A, Alfonso-Jaume MA, Lovett DH: Inhibition of MMP2/MMP9 after spinal cord trauma reduces apoptosis. Spine (Phila Pa 1976) 2008, 33:E576-E579.

41. Chen KB, Uchida K, Nakajima H, Yayama T, Hirai T, Watanabe S, Guerrero AR, Kobayashi S, Ma WY, Liu SY, Baba H: Tumor necrosis factor-alpha antagonist reduces apoptosis of neurons and oligodendroglia in rat spinal cord injury. Spine (Phila Pa 1976) 2011, 36:1350-1358.

42. Ogawa S, Kitao Y, Hori O: Ischemia-induced neuronal cell death and stress response. Antioxid Redox Signal 2007, 9:573-587.

43. DeGracia DJ, Montie HL: Cerebral ischemia and the unfolded protein response. J Neurochem 2004, 91:1-8.

44. Ling ZQ, Tian Q, Wang L, Fu ZQ, Wang XC, Wang Q, Wang JZ: Constant illumination induces Alzheimer-like damages with endoplasmic reticulum involvement and the protection of melatonin. J Alzheimers Dis 2009, 16:287-300.

45. Silva RM, Ries V, Oo TF, Yarygina O, Jackson-Lewis V, Ryu EJ, Lu PD, Marciniak SJ, Ron D, Przedborski S, Kholodilov N, Greene LA, Burke RE: CHOP/ GADD153 is a mediator of apoptotic death in substantia nigra dopamine neurons in an in vivo neurotoxin model of parkinsonism. J Neurochem 2005, 95:974-986.

46. Wang Z, Zhang C, Hong Z, Chen H, Chen W, Chen G: C/EBP homologous protein (CHOP) mediates neuronal apoptosis in rats with spinal cord injury. Exp Ther Med 2013, 5:107-111.

47. Kaplan DR, Miller FD: Signal transduction by the neurotrophin receptors. Curr Opin Cell Biol 1997, 9:213-221.

48. Mirlashari MR, Randen I, Kjeldsen-Kragh J: Glycogen synthase kinase-3 (GSK-3) inhibition induces apoptosis in leukemic cells through mitochondria-dependent pathway. Leuk Res 2012, 36:499-508.

49. Park SJ, Kim SH, Choi HS, Rhee Y, Lim SK: Fibroblast growth factor 2-induced cytoplasmic asparaginyl-tRNA synthetase promotes survival of osteoblasts by regulating anti-apoptotic PI3K/Akt signaling. Bone 2009, 45:994-1003.

50. Ma Y, Liu W, Wang Y, Chao X, Qu Y, Wang K, Fei Z: VEGF protects rat cortical neurons from mechanical trauma injury induced apoptosis via the MEK/ERK pathway. Brain Res Bull 2011, 86:441-446.

51. Ketschek A, Gallo G: Nerve growth factor induces axonal filopodia through localized microdomains of phosphoinositide 3-kinase activity that drive the formation of cytoskeletal precursors to filopodia. J Neurosci 2010, 30:12185-12197.

52. Zhu W, Oxford GS: Differential gene expression of neonatal and adult DRG neurons correlates with the differential sensitization of TRPV1 responses to nerve growth factor. Neurosci Lett 2011, 500:192-196.

53. Scuteri A, Galimberti A, Ravasi M, Pasini S, Donzelli E, Cavaletti G, Tredici G: NGF protects dorsal root ganglion neurons from oxaliplatin by modulating JNK/Sapk and ERK1/2. Neurosci Lett 2010, 486:141-145.

\section{doi:10.1186/1479-5876-12-130}

Cite this article as: Zhang et al:: Nerve growth factor improves functional recovery by inhibiting endoplasmic reticulum stress-induced neuronal apoptosis in rats with spinal cord injury. Journal of Translational Medicine 2014 12:130

\section{Submit your next manuscript to BioMed Central and take full advantage of:}

- Convenient online submission

- Thorough peer review

- No space constraints or color figure charges

- Immediate publication on acceptance

- Inclusion in PubMed, CAS, Scopus and Google Scholar

- Research which is freely available for redistribution

Submit your manuscript at www.biomedcentral.com/submit 